\title{
Substance Usage End Timepoint
}

National Cancer Institute

\section{Source}

National Cancer Institute. Substance Usage End Timepoint. NCI Thesaurus. Code C88003.

A point in time that indicates the conclusion of substance usage. 